\title{
Effect of step edges on the growth of Pt thin films on oxide single-crystal substrates
}

\author{
Tadashi SHIOTA, ${ }^{\dagger}$ Hiroki ITO, Naoki WAKIYA, ${ }^{*}$ Jeffrey CROSS, Osamu SAKURAI and Kazuo SHINOZAKI
}

\author{
Department of Metallurgy and Ceramics Science, Graduate School of Science and Engineering, \\ Tokyo Institute of Technology, 2-12-1 Ookayama, Meguro-ku, Tokyo 152-8552, Japan \\ *Department of Materials Science and Chemical Engineering, Shizuoka University, \\ 3-5-1 Johoku, Naka-ku, Hamamatsu 432-8561, Japan
}

To study the effect of step edges on the growth of Pt thin films on oxide substrates, $\mathrm{Pt}$ films were grown on $\mathrm{SrTiO}_{3}(100)$, rutile $\mathrm{TiO}_{2}(100)$, and $\mathrm{Al}_{2} \mathrm{O}_{3}(11-20)$ stepped surfaces at 673 and $973 \mathrm{~K}$ by pulsed laser deposition. No clear effect due to the step edges on the film growth was found on the $\mathrm{SrTiO}_{3}$ at $673 \mathrm{~K}$. However, the Pt grains were larger in size at the step edges than on the terraces at $973 \mathrm{~K}$. The estimated length of the Pt surface diffusion was longer than the average terrace width at $973 \mathrm{~K}$ and shorter at $673 \mathrm{~K}$. Similar growth behavior was also observed on the $\mathrm{TiO}_{2}$ at $973 \mathrm{~K}$, while there was no clear effect caused by the step edges in the case of the $\mathrm{Al}_{2} \mathrm{O}_{3}$. The Pt diffusion length was estimated to be longer than the terrace width on the $\mathrm{TiO}_{2}$ and shorter on the $\mathrm{Al}_{2} \mathrm{O}_{3}$. The effect of the step edges can therefore be understood by considering the Pt surface diffusion.

(-2013 The Ceramic Society of Japan. All rights reserved.

Key-words : Thin film growth, Oxide single crystal, Stepped surface, Platinum, Surface diffusion

[Received October 2, 2012; Accepted January 12, 2013]

\section{Introduction}

Oxide-supported Pt thin films have been widely used for electrodes and catalysts in industry. Recently, a reduction in Pt usage is required owing to the diminishing reserves; therefore, improvements in the efficiency of the electrodes and catalysts are needed. Using nanostructures such as nanowires, nanorods, and nanoclusters could be one way to achieve this, because nanostructures have larger surface areas where catalytic or chemical reactions occur. ${ }^{1)}$ Furthermore, these Pt nanostructures are expected to have interesting electrical, optical, and magnetic properties. Ogata et al. fabricated Pt nanowires, with a boomerang-like cross-section, on $\mathrm{MgO}(110)$ by shadow deposition and reported their optical second-harmonic generation response. ${ }^{2), 3)}$ Yang et al. carried out a first-principles calculation on the electronic structure of $\mathrm{Pt}$ ultrathin films grown on $\mathrm{MgO}(001)$, and predicted that a Pt film with one monolayer thickness would be ferromagnetic. ${ }^{4)}$

One of the methods used to fabricate a nanostructure, particularly a nanowire, is to use a stepped surface as a template. ${ }^{5)}$ Penner et al. succeeded in fabricating metal nanowires, along the step edges, on highly oriented pyrolytic graphite, using an electrodeposition method. ${ }^{6), 7)}$ Himpsel et al. reported the use of Si stepped surfaces as templates for fabricating nanowires. ${ }^{8)}$ As far as the authors know, however, only a few studies are conducted on the fabrication of metallic nanowires on oxide stepped substrates. In this study, Pt thin films were grown on the stepped surface of single-crystal oxides to study the effect of the step edges on the film growth and discuss the possibility of fabricating nanowires with surfaces such as these.

\section{Experimental procedure}

Stepped surfaces of $\mathrm{SrTiO}_{3}(100)$, rutile $\mathrm{TiO}_{2}(100)$, and $\mathrm{Al}_{2} \mathrm{O}_{3}(11-20)$ single crystals (Sinkosha Co., Ltd.) of $10 \mathrm{~mm} \times$

\footnotetext{
Correponding author: T. Shiota; E-mail: tshiota@ceram.titech. ac.jp
}

$10 \mathrm{~mm} \times 0.5 \mathrm{~mm}$ size were used as substrates. The $\mathrm{SrTiO}_{3}(100)$ and $\mathrm{Al}_{2} \mathrm{O}_{3}(11-20)$ substrates were annealed in air at $1273 \mathrm{~K}$ for $2 \mathrm{~h}$ and at $1373 \mathrm{~K}$ for $2 \mathrm{~h}$, respectively. Figures 1(a)-1(c) show the atomic force microscope (AFM) images of the $\mathrm{SrTiO}_{3}, \mathrm{TiO}_{2}$, and $\mathrm{Al}_{2} \mathrm{O}_{3}$ with a scanned area of $1 \mu \mathrm{m} \times 1 \mu \mathrm{m}$. All the substrates have almost linear monoatomic step edges. Before deposition, these substrates were cleaned with isopropanol using an ultrasonic bath and placed into a vacuum chamber. The Pt thin film was grown by a pulsed laser deposition (PLD) technique using a COMPex102 series $\mathrm{KrF}$ excimer laser $(\lambda=248 \mathrm{~nm}$, pulse duration $=30 \mathrm{~ns}$ ) from Lambda Physik. The laser was operated at a repetition rate of $3 \mathrm{~Hz}$ with a laser fluence of about $1.9 \mathrm{~J} / \mathrm{cm}^{2}$ at the target. A $99.9 \%$ Pt disk was used as a target with a diameter of $20 \mathrm{~mm}$ and thickness of $1 \mathrm{~mm}$. During the PLD, the substrate temperature was either $673 \mathrm{~K}$ or $973 \mathrm{~K}$, and the background pressure was maintained below $6.7 \times 10^{-4} \mathrm{~Pa}$. The crystalline orientation of the films was determined by X-ray diffraction (XRD) using $\mathrm{Cu} K \alpha$ radiation. The surface morphology of the film was observed by a tapping-mode AFM (Nanoscope 3a, Digital Instruments) at room temperature in air.

\section{Results and discussion}

To understand the growth behavior of the Pt film on each substrate at $673 \mathrm{~K}$ and $973 \mathrm{~K}$, the films were deposited for $30 \mathrm{~min}$ on the $\mathrm{SrTiO}_{3}, 3 \mathrm{~h}$ on the $\mathrm{TiO}_{2}$, and $3 \mathrm{~h}$ on the $\mathrm{Al}_{2} \mathrm{O}_{3}$. Their crystalline orientations are summarized in Table 1. The Pt thin film grown on the $\mathrm{SrTiO}_{3}$ at $973 \mathrm{~K}$ had an epitaxial (100) orientation. The thickness of the epitaxial film was determined to be $9.7 \mathrm{~nm}$ from the period of the thickness fringes in the XRD pattern, and the growth rate was calculated to be $0.32 \mathrm{~nm} / \mathrm{min}$. On the other hand, at $673 \mathrm{~K}$, a (111)-oriented film was obtained. The film thickness was determined to be $6.5 \mathrm{~nm}$ from the period of the fringes in X-ray reflectivity (XRR) curve, and the growth rate was calculated to be $0.22 \mathrm{~nm} / \mathrm{min}$. Moreover, (111)-oriented films were grown on all other substrates at both $673 \mathrm{~K}$ and $973 \mathrm{~K}$. The film thickness on the $\mathrm{Al}_{2} \mathrm{O}_{3}$ was also determined by the XRR 


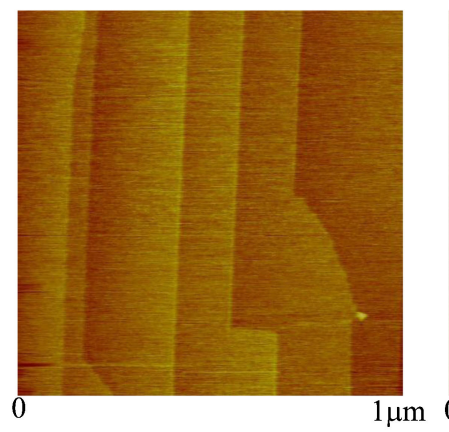

(a) $\mathrm{SrTiO}_{3}(100)$

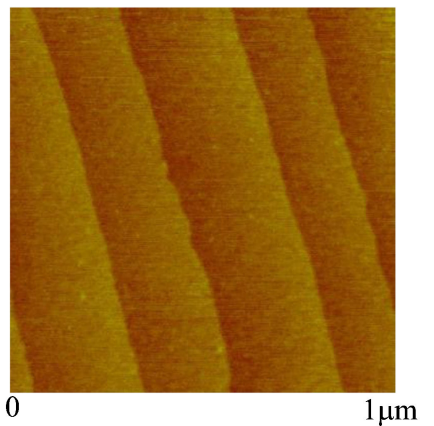

(b) $\mathrm{TiO}_{2}(100)$

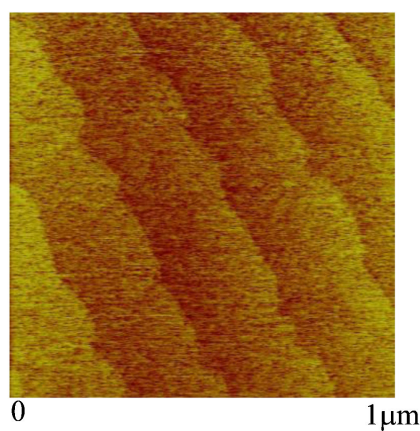

(c) $\mathrm{Al}_{2} \mathrm{O}_{3}(11-20)$

Fig. 1. (Color online) The AFM images of clean stepped surfaces of (a) $\mathrm{SrTiO}_{3}(100)$, (b) rutile $\mathrm{TiO}_{2}(100)$, and (c) $\mathrm{Al}_{2} \mathrm{O}_{3}$ (11-20) substrates. The scanned area was $1 \mu \mathrm{m} \times 1 \mu \mathrm{m}$. The $\mathrm{SrTiO}_{3}$ and $\mathrm{Al}_{2} \mathrm{O}_{3}$ were annealed in air at $1273 \mathrm{~K}$ for $2 \mathrm{~h}$ and at $1373 \mathrm{~K}$ for $2 \mathrm{~h}$, respectively.

Table 1. Crystalline orientations of the Pt thin films grown at 673 and $973 \mathrm{~K}$ on the $\mathrm{SrTiO}_{3}, \mathrm{TiO}_{2}$, and $\mathrm{Al}_{2} \mathrm{O}_{3}$ stepped substrates

\begin{tabular}{lcc}
\hline \multirow{2}{*}{ Substrate } & \multicolumn{2}{c}{ Substrate temperature } \\
\cline { 2 - 3 } & $673 \mathrm{~K}$ & $973 \mathrm{~K}$ \\
\hline $\mathrm{SrTiO}_{3}(100)$ & $(111)$ & epitaxial $(100)$ \\
$\mathrm{TiO}_{2}(100)$ & $(111)$ & $(111)$ \\
$\mathrm{Al}_{2} \mathrm{O}_{3}(11-20)$ & $(111)$ & $(111)$ \\
\hline
\end{tabular}

method. The thickness of the film grown at $973 \mathrm{~K}$ was $8.6 \mathrm{~nm}$ and the growth rate was $0.048 \mathrm{~nm} / \mathrm{min}$. The film thickness on the $\mathrm{TiO}_{2}$ was determined by measuring the step height using the tapping-mode AFM. The step was created by masking part of the substrate with a small piece of stainless steel during the PLD. The thickness of the film deposited at $973 \mathrm{~K}$ was $10.5 \mathrm{~nm}$ and the growth rate was calculated to be $0.058 \mathrm{~nm} / \mathrm{min}$. Because the lattice constant mismatch is small between the $\mathrm{SrTiO}_{3}(100)$ and $\mathrm{Pt}(100)$, the Pt film is epitaxially grown at $973 \mathrm{~K}$. When the substrate temperature is reduced to $673 \mathrm{~K}$, the (111)-oriented film grows according to the preferential (for Pt) energetics. This agrees with the previously reported results. $\left.{ }^{9}\right)$ On the $\mathrm{TiO}_{2}$ and $\mathrm{Al}_{2} \mathrm{O}_{3}$ substrates, the lattice mismatch is larger, and therefore the (111)-oriented films are obtained.

Figure 2 shows an AFM image of the Pt thin film grown on the $\mathrm{SrTiO}_{3}(100)$ at $673 \mathrm{~K}$ for $15 \mathrm{~min}$. The scanned area was 500 $\mathrm{nm} \times 500 \mathrm{~nm}$. The average thickness of the film was estimated from the deposition rate to be $3.3 \mathrm{~nm}$. The step edges were clearly seen even after the Pt deposition. To clarify the effect of the step edges on the growth behavior, grain size distributions were determined from the AFM image as a function of the distance from the step edge. Figure 3 shows the grain size distributions on the lines (a)-(d) shown in Fig. 2. Line (d) is on the step edge and line (a) on the lower terrace near the step edge. The terrace between lines (a) and (d) is equally divided by the lines (b) and (c). In Fig. 3, no clear effect of the step edge is seen in the case of $\mathrm{SrTiO}_{3}$ at $673 \mathrm{~K}$. In contrast, the step edge clearly affected the thin film growth at $973 \mathrm{~K}$. Figure 4 shows the $500 \mathrm{~nm} \times 500 \mathrm{~nm}$ AFM image of the Pt thin film grown at $973 \mathrm{~K}$ for $15 \mathrm{~min}$. The film thickness was estimated to be $4.8 \mathrm{~nm}$. Figure 5 shows the grain size distributions on the lines (a)-(d) shown in Fig. 4. The number of Pt grains with the sizes ranging from $10 \mathrm{~nm}$ to $15 \mathrm{~nm}$ was the largest on the lines (a), (b), and (c). Note that the average grain size on the line (b) was the smallest. This suggests that more Pt adatoms around line (b) diffused away and were trapped in other areas, such as the step edge. The grain size distribution

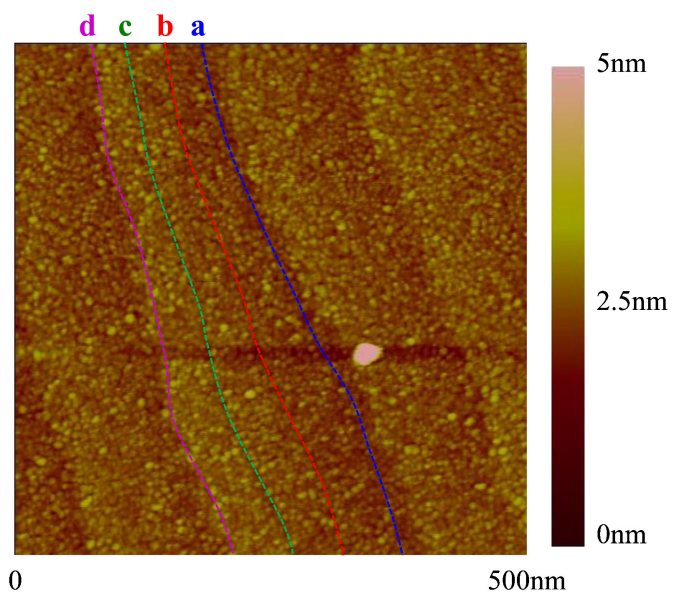

Fig. 2. (Color online) The $500 \mathrm{~nm} \times 500 \mathrm{~nm}$ AFM image of the Pt thin film grown on the $\mathrm{SrTiO}_{3}(100)$ stepped surface at $673 \mathrm{~K}$.

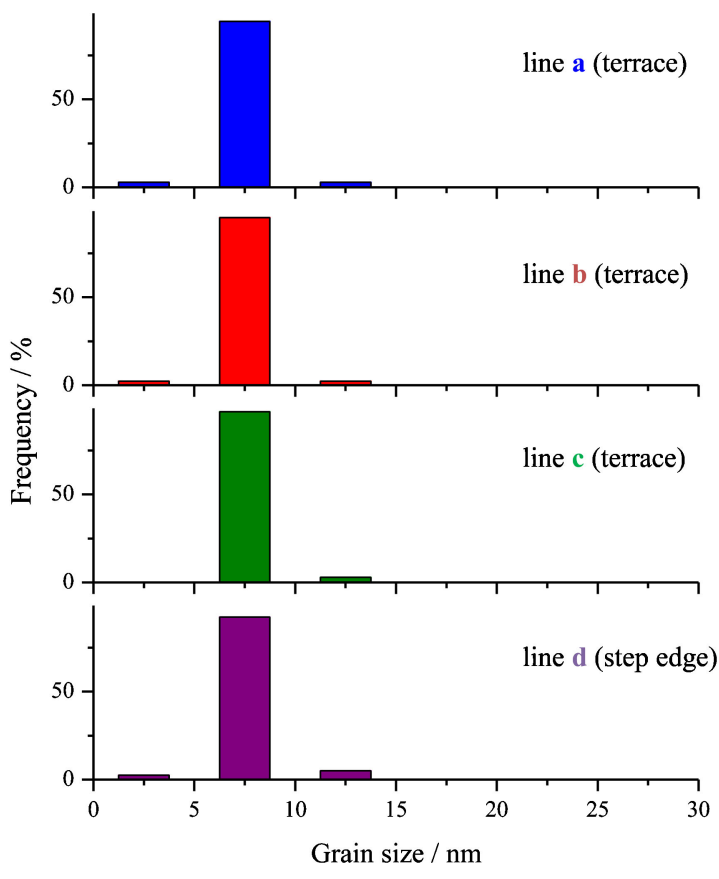

Fig. 3. (Color online) Grain size distributions in the Pt thin film grown at $673 \mathrm{~K}$ on the $\mathrm{SrTiO}_{3}$ stepped surface as a function of the distance from the step edge. 


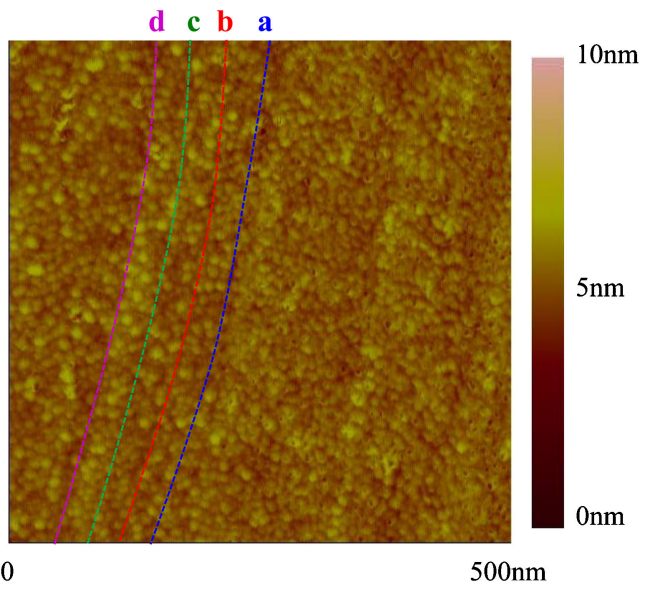

Fig. 4. (Color online) The $500 \mathrm{~nm} \times 500 \mathrm{~nm}$ AFM image of the Pt thin film grown on the $\mathrm{SrTiO}_{3}(100)$ stepped surface at $973 \mathrm{~K}$.

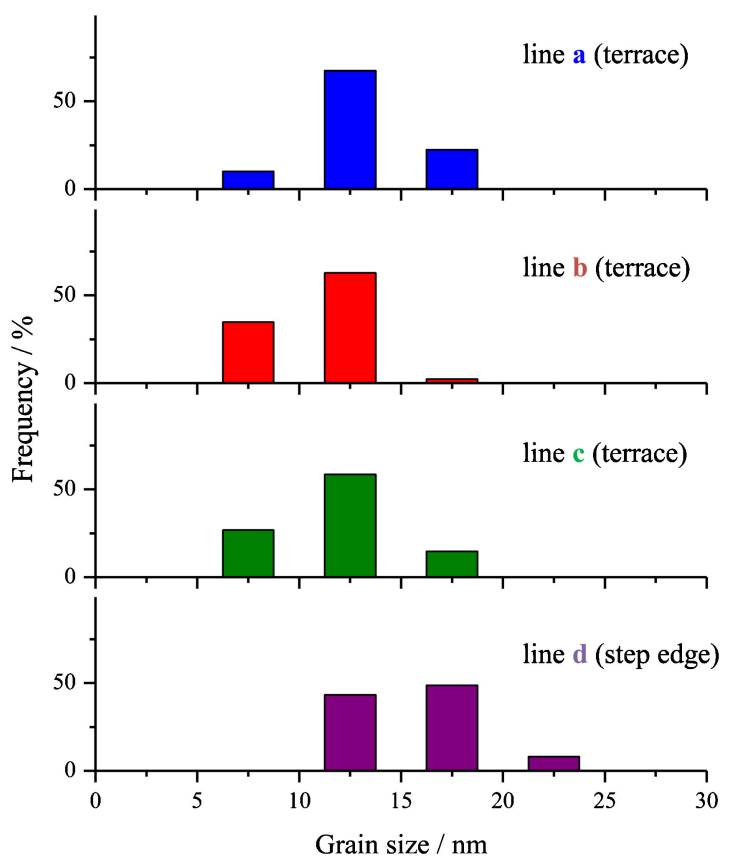

Fig. 5. (Color online) Grain size distributions in the Pt thin film grown at $973 \mathrm{~K}$ on the $\mathrm{SrTiO}_{3}$ stepped surface as a function of the distance from the step edge.

on line (d) was shifted to larger sizes, indicating that the Pt grains were preferentially grown at the step edges on the $\mathrm{SrTiO}_{3}$ at $973 \mathrm{~K}$.

The difference in the growth behavior can be attributed to the temperature dependence of the Pt surface diffusion. An average diffusion length $l_{\mathrm{d}}$ can be estimated from the following equation:

$$
l_{\mathrm{d}}=\sqrt{D_{\mathrm{s}} t_{\mathrm{d}}},
$$

where $D_{\mathrm{s}}$ and $t_{\mathrm{d}}$ are the diffusion coefficients and the time for diffusion, respectively. Because metal diffusion on oxide surfaces has not yet been quantified, Francis et al. ${ }^{9)}$ and Christensen et al. ${ }^{10)}$ used the following empirical equation for surface selfdiffusion of face-centered cubic metals proposed by Gjostein ${ }^{11)}$ to explain the growth process of $\mathrm{Pt}$ thin film on $\mathrm{SrTiO}_{3}(100)$ :

$$
D_{\mathrm{s}}=0.014 \exp \left(\frac{-13 T_{\mathrm{m}}}{R_{\mathrm{c}} T}\right)
$$

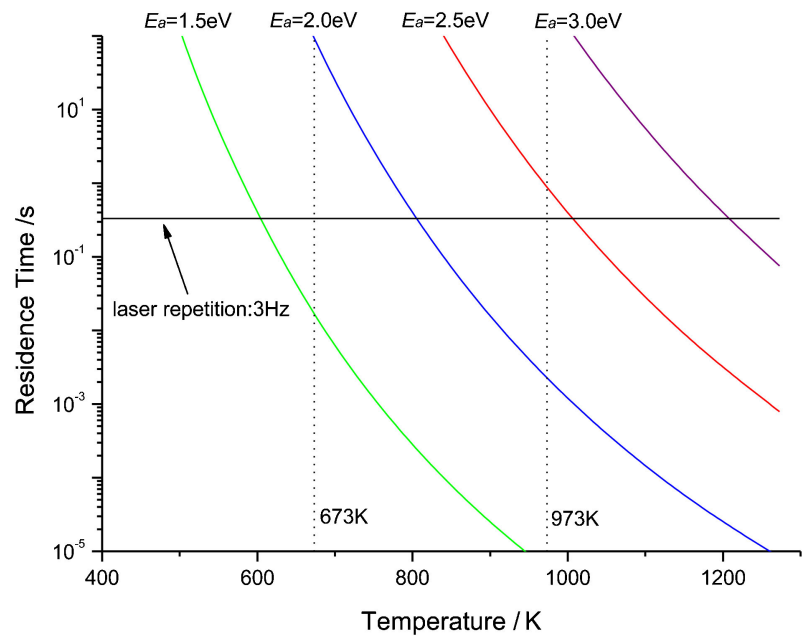

Fig. 6. (Color online) The $E_{\mathrm{a}}$ and temperature dependence of the residence time $\tau$ calculated from Eq. (3).

where $R_{\mathrm{c}}, T_{\mathrm{m}}$, and $T$ are the gas constant, melting point, and substrate temperature, respectively. The $t_{\mathrm{d}}$ should be determined as follows. The ablated atoms that were deposited on a substrate surface can diffuse for a residence time $\tau$. The $\tau$ depends on the adsorption energy $E_{\mathrm{a}}$ and is expressed by the following equation: ${ }^{1)}$

$$
\tau=\frac{1}{v} \exp \left(\frac{E_{\mathrm{a}}}{k T}\right)
$$

where $v, k$, and $T$ are the atomic vibration frequency $\left(\sim 10^{13}\right)$, Boltzmann constant, and temperature, respectively. Figure 6 shows dependence of the $\tau$ calculated from Eq. (3) on $E_{\mathrm{a}}$ and temperature. The time between the laser pulses $(3 \mathrm{~Hz})$ is also shown. To determine the $t_{\mathrm{d}}$, the $\tau$ and the time between the laser pulses are compared, and then the shorter time is determined as the $t_{\mathrm{d}}$.

The $\mathrm{SrTiO}_{3}(100)$ substrate used in this study was etched with a buffered hydrofluoric acid and annealed in air at $1273 \mathrm{~K}$. After treatment, a $\mathrm{TiO}_{2}$-terminated surface is obtained. ${ }^{12), 13)}$ Asthagiri et al. used the density functional theory (DFT) within the local density approximation to calculate the $E_{\mathrm{a}}$ of the Pt atom on the $\mathrm{TiO}_{2}$-terminated surface with a half monolayer of the Pt. ${ }^{14)}$ They reported an $E_{\mathrm{a}}$ of $2.18 \mathrm{eV}$ on top of a Ti atom, of $2.64 \mathrm{eV}$ on a fourfold hollow site, and of $3.47 \mathrm{eV}$ on top of an oxygen atom. The average of these values was used as the $E_{\mathrm{a}}$, and then $\tau$ was calculated from Eq. (3) to be $5.0 \times 10^{7} \mathrm{~s}$ at $673 \mathrm{~K}$ and $21 \mathrm{~s}$ at $973 \mathrm{~K}$, respectively. Both these $\tau$ values are longer than the time between the laser pulses. Therefore, the time between the laser pulses was determined as the $t_{\mathrm{d}}$. The average diffusion length was estimated from Eqs. (1) and (2) to be $33 \mathrm{~nm}$ at $673 \mathrm{~K}$ and $710 \mathrm{~nm}$ at $973 \mathrm{~K}$. Because the terrace width on the substrate was measured in the AFM image to be $219 \mathrm{~nm} \pm 36 \mathrm{~nm}$, the estimated diffusion length is longer than the terrace width at $973 \mathrm{~K}$ and shorter at $673 \mathrm{~K}$. Therefore, the temperature dependence of the growth behavior on the $\mathrm{SrTiO}_{3}$ can be explained as shown in Fig. 7. The Pt atoms evaporated by the laser ablation reach the substrate and diffuse on the surface. The diffusion length depends on the substrate temperature [Figs. 7(a) and 7(c)]. At $673 \mathrm{~K}$, most of the diffused atoms cannot reach the step edges and are incorporated into the grains on the terrace owing to the shorter diffusion length. This leads to uniform grain growth [Fig. 7(b)]. On the other hand, because the diffusion length is longer at $973 \mathrm{~K}$, many Pt atoms reach the step edges and are trapped. 


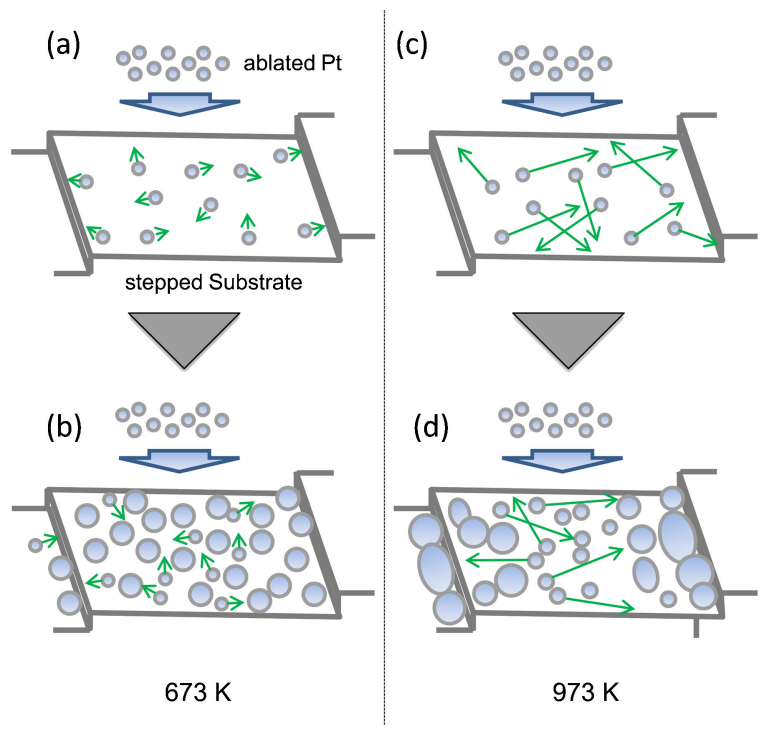

Fig. 7. (Color online) A schematic model of the Pt thin film growth on the stepped surface of the $\mathrm{SrTiO}_{3}$ at $673 \mathrm{~K}$ [(a) and (b)] and $973 \mathrm{~K}$ [(c) and (d)] by PLD.

Therefore, the grains grow larger at the step edge than on the terrace [Fig. 7(d)].

Figures 8(a) and 8(b) show the grain size distributions in the films grown for $15 \mathrm{~min}$ at $973 \mathrm{~K}$ on the $\mathrm{TiO}_{2}(100)$ and $\mathrm{Al}_{2} \mathrm{O}_{3}$ (11-20) substrates, respectively. The thickness of the film was estimated to be $0.88 \mathrm{~nm}$ on the $\mathrm{TiO}_{2}$ and $0.72 \mathrm{~nm}$ on the $\mathrm{Al}_{2} \mathrm{O}_{3}$. On the $\mathrm{TiO}_{2}$ substrates, the $\mathrm{Pt}$ grain size at the step edges was larger than on the terrace, which is similar to the growth behavior on the $\mathrm{SrTiO}_{3}$. Although the $E_{\mathrm{a}}$ of the Pt on the rutile $\mathrm{TiO}_{2}(100)$ has not been determined, that on the rutile $\mathrm{TiO}_{2}(110)$ was calculated to be $2.32 \mathrm{eV}$ from DFT calculations. ${ }^{15)}$ The $\tau$ at $973 \mathrm{~K}$ was calculated to be $0.10 \mathrm{~s}$. Because the $\tau$ was smaller than the time between the laser pulses, the calculated $\tau$ was determined as the $t_{\mathrm{d}}$. The diffusion length was estimated to be $400 \mathrm{~nm}$. In the AFM image, the terrace width of the $\mathrm{TiO}_{2}$ was measured to be $281 \mathrm{~nm} \pm 20 \mathrm{~nm}$. The estimated diffusion length is therefore longer than the average terrace width. This is the reason why the growth behavior on the $\mathrm{TiO}_{2}$ was similar to that on the $\mathrm{SrTiO}_{3}$.

Larger grain growth at the step edges was not clearly seen on the $\mathrm{Al}_{2} \mathrm{O}_{3}$, which differs from the growth behavior on $\mathrm{SrTiO}_{3}$ and $\mathrm{TiO}_{2}$. There has been no report on the $E_{\mathrm{a}}$ of the Pt on the $\mathrm{Al}_{2} \mathrm{O}_{3}(11-20)$. However, Briquet et al. ${ }^{16)}$ and Hinnemann et al. ${ }^{17)}$ calculated the $E_{\mathrm{a}}$ on $\mathrm{Al}_{2} \mathrm{O}_{3}(0001)$ using first-principles calculation, and reported values of 1.99 and $2.02 \mathrm{eV}$, respectively. The average of these values was used as the $E_{\mathrm{a}}$, and the $\tau$ at $973 \mathrm{~K}$ was calculated to be $2.4 \times 10^{-3} \mathrm{~s}$. This was shorter than the time between the laser pulses, and therefore the calculated $\tau$ was used as the $t_{\mathrm{d}}$. The diffusion length was estimated to be $61 \mathrm{~nm}$. The terrace width was measured in the AFM image to be $249 \mathrm{~nm} \pm$ $18 \mathrm{~nm}$. Thus, because the estimated diffusion length is shorter than the average terrace width, Pt grains grow on the terrace as well as at the step edges.

As seen in Figs. 5 and 8(a), it is clearly observed that the Pt grains are preferentially grown at the step edges on the $\mathrm{SrTiO}_{3}$ (100) and $\mathrm{TiO}_{2}(100)$ surfaces at $973 \mathrm{~K}$. However, Pt grains with a smaller size are also observed on the terraces, as shown in Figs. 2 and 4. Diffusing Pt atoms on oxide surfaces are trapped not only by step edges but also by oxygen vacancies, and these Pt atoms form nuclei for subsequent grain growth; ${ }^{1)}$ this is supported by

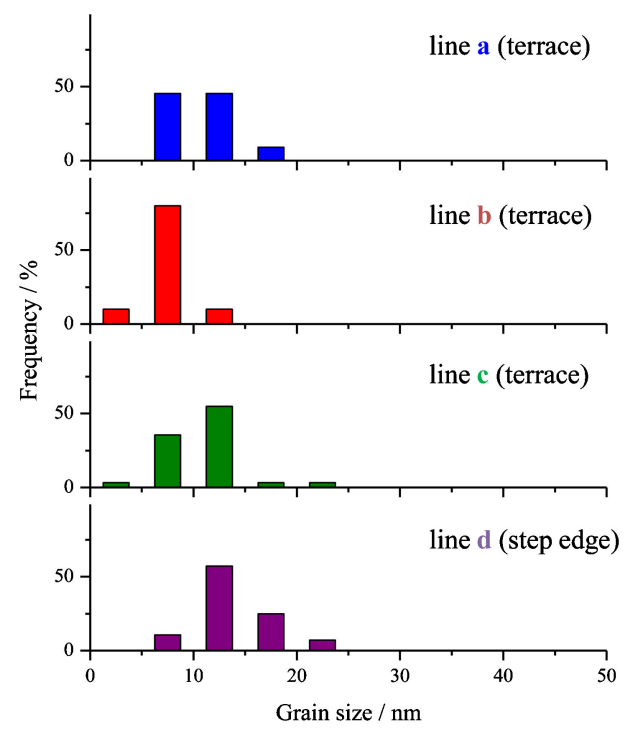

(a) $\mathrm{TiO}_{2}(100)$

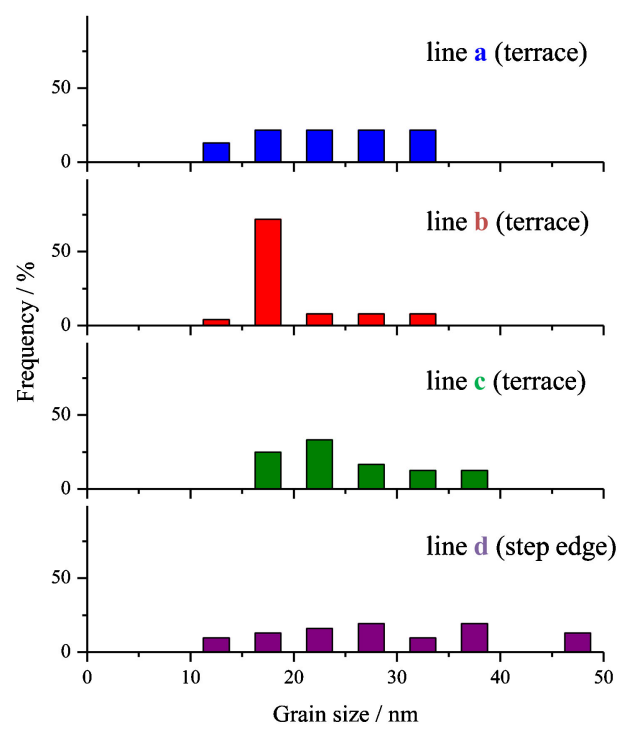

(b) $\mathrm{Al}_{2} \mathrm{O}_{3}(11-20)$

Fig. 8. (Color online) Grain size distributions in the Pt thin film grown at $973 \mathrm{~K}$ on the (a) $\mathrm{TiO}_{2}(100)$ and (b) $\mathrm{Al}_{2} \mathrm{O}_{3}(11-20)$ stepped surfaces as a function of the distance from the step edge.

many studies. For example, it has been shown from DFT calculations that the $E_{\mathrm{a}}$ of the Pt atom is larger at oxygen vacancy sites on $\mathrm{TiO}_{2}$ surfaces. ${ }^{15), 18)}$ In this study, the Pt thin film was grown on the oxide substrates by the PLD technique. In the PLD technique, the oxide substrate was heated in a high vacuum, meaning that oxygen vacancies would be formed on the substrate surface. ${ }^{19)}$ Therefore, the Pt adatoms were captured by the oxygen vacancies as well as the step edges, and the Pt grains were also grown on the terrace. Based on the above discussion, it is believed that it would be difficult to fabricate Pt nanowires on oxide surfaces using the method outlined in this study, i.e., using the stepped surface as a template.

\section{Conclusion}

Pt thin films were grown by a PLD technique on $\mathrm{SrTiO}_{3}(100)$, rutile $\mathrm{TiO}_{2}(100)$, and $\mathrm{Al}_{2} \mathrm{O}_{3}(11-20)$ stepped surfaces at 673 and $973 \mathrm{~K}$ in order to study the effect of step edges on thin film 
growth. The grain size was uniform in the Pt thin film grown on $\mathrm{SrTiO}_{3}$ at $673 \mathrm{~K}$, while larger grains grew at the step edge than on the terrace at $973 \mathrm{~K}$. Thus, a clear effect of the step edges was seen in the thin film growth at $973 \mathrm{~K}$. The length of the Pt surface diffusion was estimated to be longer than the terrace width at $973 \mathrm{~K}$ and shorter at $673 \mathrm{~K}$. On the $\mathrm{TiO}_{2}$ at $973 \mathrm{~K}$, a similar effect of the step edges was observed, and the estimated diffusion length was also longer than the terrace width. In contrast, on the $\mathrm{Al}_{2} \mathrm{O}_{3}$, there was no clear effect of the step edges, because the estimated diffusion length was shorter than the terrace width. Thus, this study experimentally shows that when step edges exist within the area where the $\mathrm{Pt}$ adatoms can diffuse, Pt grains are preferentially grown there.

\section{References}

1) Q. Fu and T. Wanger, Surf. Sci. Rep., 62, 431-498 (2007).

2) Y. Ogata, N. Tuan, S. Takase and G. Mizutani, Surf. Interface Anal., 42, 1663-1666 (2010).

3) Y. Ogata, N. A. Tuan, Y. Miyauchi and G. Mizutani, J. Appl. Phys., 110, 044301 (2011)

4) L. H. Yang, J. Park and B. D. Yu, J. Korea. Phys. Soc., 56, 791-795 (2010).

5) B. Y. Xia, P. Yang, Y. Sun, Y. Wu, B. Mayers, B. Gates, Y. Yin, F. Kim and H. Yan, Adv. Mater., 15, 353-389 (2003).

6) R. M. Penner, J. Phys. Chem. B, 106, 3339-3353 (2002).

7) E. C. Walter, B. J. Murray, F. Favier, G. Kaltenpoth, M. Grunze and R. M. Penner, J. Phys. Chem. B, 106, 11407-11411 (2002).

8) F. J. Himpsel, A. Kirakosian, J. N. Crain, J.-L. Lin and D. Y. Petrovykh, Solid State Commun., 117, 149-157 (2001).

9) A. J. Francis and P. A. Salvador, J. Mater. Res., 22, 89-102 (2007).

10) S. T. Christensen, J. W. Elam, B. Lee, Z. Feng, M. J. Bedzyk and M. C. Hersam, Chem. Mater., 21, 516-521 (2009).

11) N. A. Gjostein, in "Surfaces and Interfaces", Ed. by J. J. Burke, N. L. Reed and V. Weiss, Syracuse University Press, Syracuse, NY (1976) pp. 271-304.

12) T. Ohnishi, K. Shibuya, M. Lippmaa, D. Kobayashi, H. Kumigashira, M. Oshima and H. Koinuma, Appl. Phys. Lett., 85, 272-274 (2004).

13) A. Biswa, P. B. Rossen, C. H. Yang, W. Siemons, M. H. Jung, I. K. Yang, R. Ramesh and Y. H. Jeong, Appl. Phys. Lett., 98, 051904 (2011).

14) A. Asthagiri and D. S. Sholl, J. Chem. Phys., 116, 9914-9925 (2002).

15) V. Celik, H. Unal, E. Mete and S. Ellialtioglu, Phys. Rev. B, 82, 205113 (2010).

16) L. G. V. Briquet, C. R. A. Catlow and S. A. French, J. Phys. Chem. C, 112, 18948-18954 (2008).

17) B. Hinnemann and E. A. Carter, J. Phys. Chem. C, 111, 71057126 (2007).

18) X. Q. Gong, A. Selloni, O. Dulub, P. Jacobson and U. Diebold, J. Am. Chem. Soc., 130, 370-381 (2008).

19) J. M. Pan, B. L. Maschhoff, U. Diebold and T. E. Madey, J. Vac. Sci. Technol., A, 10, 2470-2476 (1992). 